\title{
Antioxidant, anti-inflammatory, anti-apoptotic, and skin regenerative properties of an Aloe vera-based extract of Nerium oleander leaves (NAE- ${ }^{\circledR}$ )
}

This article was published in the following Dove Press journal:

Clinical, Cosmetic and Investigational Dermatology

6 May 2015

Number of times this article has been viewed

\section{Kathleen F Benson' \\ Robert A Newman ${ }^{2,3}$ \\ Gitte S Jensen'}

'NIS Labs, Klamath Falls, Oregon, USA; ${ }^{2}$ University of Texas MD

Anderson Cancer Center, Houston, TX, USA; ${ }^{3}$ Nerium Biotechnology, Inc, San Antonio, TX, USA

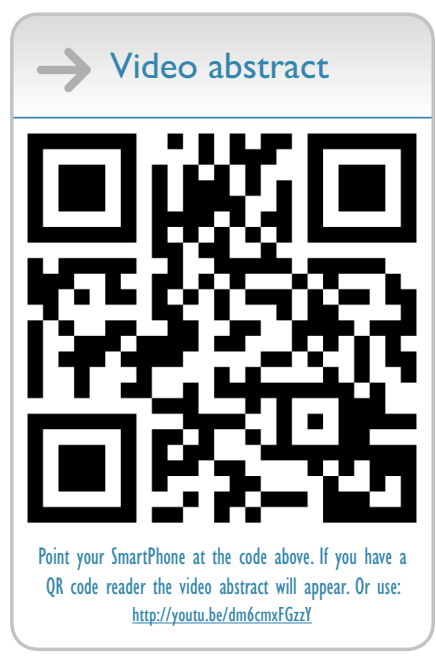

Correspondence: Robert A Newman II 2 Whale Rock Lane

Surry, ME 04684, UK

Tel +I 2076675214

Email newmanscientificconsulting@gmail. com
Objective: The goal for this study was to evaluate the effects of an Aloe vera-based Nerium oleander extract (NAE- $8^{\circledR}$ ), compared to an extract of $A$. vera gel alone (ALOE), and to an aqueous extract of $N$. oleander (AQ-NOE) in bioassays pertaining to dermatologic potential with respect to antioxidant protection, anti-inflammatory effects, and cytokine profiles in vitro.

Methods: Cellular antioxidant protection was evaluated in three separate bioassays: The cellular antioxidant protection of erythrocytes (CAP-e) assay, protection of cellular viability and prevention of apoptosis, and protection of intracellular reduced glutathione levels, where the last two assays were performed using human primary dermal fibroblasts. Reduction of intracellular formation of reactive oxygen species (ROS) was tested using polymorphonuclear cells in the absence and presence of oxidative stress. Changes to cytokine and chemokine profiles when whole blood cells and human primary dermal fibroblasts were exposed to test products were determined using a 40-plex Luminex array as a method for exploring the potential cross-talk between circulating and skin-resident cells.

Results: The NAE- $8^{\circledR}$ provided significantly better antioxidant protection in the CAP-e bioassay than AQ-NOE. NAE- $8^{\circledR}$ and AQ-NOE both protected cellular viability and intracellular reduced glutathione, and reduced the ROS formation significantly when compared to control cells, both under inflamed and neutral culture conditions. ALOE showed minimal effect in these bioassays. In contrast to the NAE- $8^{\circledR}$, the AQ-NOE showed induction of inflammation in the whole blood cultures, as evidenced by the high induction of CD69 expression and secretion of a number of inflammatory cytokines. The treatment of dermal fibroblasts with NAE- $8{ }^{\circledR}$ resulted in selective secretion of cytokines involved in collagen and hyaluronan production as well as re-epithelialization during wound healing.

Conclusion: NAE- $8^{\circledR}$, a novel component of a commercial cosmetic product, showed beneficial antioxidant protection in several cellular models, without the induction of leukocyte activation and secretion of inflammatory cytokines. The biological efficacy of NAE- ${ }^{\circledR}$ was unique from both ALOE and AQ-NOE.

Keywords: CAP-e bioassay, dermal fibroblasts, oxidative damage, ROS formation, safety

\section{Introduction}

Historical use as well as recent clinical and laboratory studies have identified the benefits of a number of natural ingredients for skin care. Consequently, a number of these plant components and extracts are being developed today not only for their "anti-aging" effects but also for a number of dermatologic disorders as well. Among the most well-known plants with regard to skin care is Aloe vera. This plant has been used for centuries with both internal as well as topical applications for a wide variety of therapeutic properties which include antibacterial, antifungal, antioxidative, and 
antiviral activities. ${ }^{1-4}$ In recent years, $A$. vera Linnaeus has become a subject of interest because of its beneficial effects on human health. This plant belongs to the family Liliaceae, is a perennial herb with $30-60 \mathrm{~cm}$ long juicy leaves, and is found growing in temperate climates in many parts of the world. To date, more than 75 active ingredients including aloesin, aloeemodin, acemannan, aloeride, methylchromones, flavonoids, saponin, amino acids, vitamins, and minerals have been identified from the inner gel of leaves. It has antiinflammatory, antioxidant, antimicrobial, anticancer, antidiabetic, immuneboosting, and hypoglycemic properties. Daily supplementation with this gel material has been reported to be effective against stroke, heart attacks, leukemia, anemia, hypertension, AIDS, radiation burns, and digestive disorders, as well as serving as a beneficial component in cosmetic products. $^{5}$

The plant Nerium oleander (synonym N. indicum Mill, and $N$. odorum Aiton) belongs to the Dogbane family Apocynaceae. It is an evergreen shrub or small tree typically growing to $2-6 \mathrm{~m}$ in height, and is cultivated all over the world, particularly in temperate climates. Leaves are in pairs of three or whorled, very green, leathery, and are narrowly elliptic to linear entire. Flowers grow in clusters in terminal branches, each $2.5-5 \mathrm{~cm}$, funnel-shaped with five lobes, fragrant, and show various colors from pink to red, white, peach, and yellow. Its ethnomedicinal uses include treatment of diverse ailments such as heart failure, asthma, corns, cancer, diabetes, and epilepsy. ${ }^{6-8}$ Less well appreciated are the skin care benefits of extracts of $N$. oleander that include antibacterial, antiviral, immune, and even antitumor properties associated with topical use..$^{9-13}$

Despite the traditional use of $N$. oleander in skin care, combined with recent findings on beneficial mechanisms of action, some controversy surrounds the perception of the safety of the use of $N$. oleander for topical use. By far, most of the toxicity associated with the generic term "oleander" is due to use and abuse of what is known as yellow oleander or Thevetia peruviana, an entirely different plant than $N$. oleander. ${ }^{14,15}$ Yellow oleander has its own unique cardiac glycoside content that includes compounds such as thevetia. In contrast, while $N$. oleander contains cardiac glycosides such as oleandrin, reports to the USA Poison Control Center database have indicated extremely rare serious adverse events associated with this specific plant. Lin et $\mathrm{al}^{13}$ and Newman et $\mathrm{al}^{16}$ have shown that while oleandrin is a potent inhibitor of human malignant melanocyte proliferation, it is not toxic to normal human cells. In fact, it has been shown that many types of human malignant cells, but not normal human cells, are growth inhibited by extracts of $N$. oleander. ${ }^{13}$ This information has, in fact, led two companies (Phoenix Biotechnology, Inc and Nerium Biotechnology, Inc) to explore the use of different extracts of $N$. oleander for anticancer activity. Beyond the content of cardiac glycosides, it is now recognized that $N$. oleander also contains many components already commonly used today in skin care products. These include, for example, the triterpenoid compounds oleanolic and ursolic acid..$^{10-12,17-21}$

While no single skin care product can truly be said to be anti-aging, there are normal aging-associated activities that are well documented to be accelerated by overexposure to sunlight (ultraviolet [UV] damage), free radicals, inflammation, and other mediators of dermal stress that do indeed accelerate the aging process with associated wrinkles and under-hydration of skin tissue. Thus, the goal of skin care health often includes support of basement membrane connective tissue and anti-oxidative support, as well as antiinflammatory and hydration measures, all of which are cited as beneficial anti-aging measures of dermal health. ${ }^{22}$

The present study was aimed at investigating the relative safety and skin health benefits of a novel $A$. vera gel-based extract of $N$. oleander (NAE- $8^{\circledR}$ ), which was designed to offer beneficial skin health benefits based on components of both plants. In the current study, the relative skin health benefits of both $A$. vera and $N$. oleander extracts were compared to the novel use of $A$. vera gel (ALOE) in order to extract beneficial molecules associated with skin health from $N$. oleander.

\section{Materials and methods Reagents}

The following reagents were purchased from Sigma-Aldrich Co (Saint Louis, MO, USA): phosphate-buffered saline (PBS), Roswell Park Memorial Institute (RPMI)-1640 medium, penicillin-streptomycin 100X, lipopolysaccharide, 0.25\% trypsin-ethylenediaminetetraacetic acid (EDTA), hydrogen peroxide, Histopaque ${ }^{\circledR}-1077$, and Histopaque ${ }^{\circledR}-1119$. The following reagents were purchased from Thermo Fisher Scientific (Waltham, MA, USA): dichlorofluorescein diacetate (DCF-DA), ThiolTracker ${ }^{\mathrm{TM}}$ Violet, Cal-Lyse ${ }^{\mathrm{TM}}$ whole blood lysing solution, and CellEvent ${ }^{\mathrm{TM}}$ Caspase-3/7 green flow cytometry assay kit. CD69 fluorescein isothiocyanate and heparin vacutainer tubes were purchased from BD (Franklin Lakes, NJ, USA). Human adult dermal fibroblasts and DF-1 fibroblast medium were purchased from Zen-Bio (Durham, NC, USA). The Bio-Plex Pro ${ }^{\mathrm{TM}}$ Human Chemokine Panel, 40-Plex was purchased from Bio-Rad Laboratories Inc (Hercules, CA, USA). 2,2'-Azobis(2-amidinopropane) 
dihydrochloride (AAPH) was purchased from Pure Chemical Industries, Ltd (Osaka, Japan).

\section{Botanical extracts}

An $A$. vera-based $N$. oleander extract (NAE- $8^{\circledR}$ ) and an aqueous-based $N$. oleander extract (AQ-NOE) were provided by Nerium Biotechnology, Inc (San Antonio, TX, USA). Aloe mucilage liquid from Aloe barbadensis served as a control and was prepared as described in US Patent No 4,957,907.23 The ALOE was obtained from the same lot as that used to perform the Aloe-based extraction of active compounds from the $N$. oleander leaves. Briefly, the ALOE was mixed with milled, dried leaves from $N$. oleander plants $(9: 1$, volume:weight). The mixture was then heated with agitation and the resulting extract filtered. Details of the extraction procedure are given in the issued US patent $8,524,286 .{ }^{24}$ The specific concentration of oleandrin in the final NAE- $8^{\circledR}$ extract was carefully monitored using state-of-the-art liquid chromatography-mass spectrometry equipment (Analytical Food Laboratories, Grand Prairie, TX, USA). This was done in order to assure extract quality and consistency from each and every extract. All further dilutions of extracts were performed using PBS as the diluent.

\section{Folin-Ciocalteu antioxidant assay}

The Folin-Ciocalteu assay (also known as the total phenolics assay) was used to examine the relative antioxidant capacity of the test products. ${ }^{25}$ This assay measured antioxidants using the Folin-Ciocalteu reagent. The Folin-Ciocalteu reagent was added to serial dilutions of products, which were then thoroughly mixed and kept at room temperature for 5 minutes. Next, color was produced by adding sodium carbonate, and the reaction was allowed to continue for 30 minutes at $37^{\circ} \mathrm{C}$. Optical density was measured with a colorimetric plate reader set to an optical absorbance of $765 \mathrm{~nm}$. The data was reported in gallic acid equivalents per $\mathrm{mL}$ of product, with gallic acid used as a reference standard.

\section{Isolation of polymorphonuclear cells and erythrocytes}

Upon written informed consent from subjects, and as approved by the Sky Lakes Medical Center Institutional Review Board (Federalwide Assurance 2603) for ethical standards, peripheral blood was drawn from healthy human donors into heparinized vacutainer tubes. Blood was layered onto a double gradient of Histopaque with densities of 1.119 and $1.077 \mathrm{~g} / \mathrm{L}$ and centrifuged at $500 \times \mathrm{g}$ for 25 minutes. Polymorphonuclear (PMN) cells and erythrocyte layers were harvested separately and cells washed with PBS, followed by centrifugation at $500 \times g$ for 10 minutes. PMN cells were washed twice and erythrocytes four times prior to use in assays.

\section{CAP-e bioassay}

In the cellular antioxidant protection of erythrocytes (CAP-e) assay, human erythrocytes were exposed to serial dilutions of test products in physiological saline for 20 minutes. ${ }^{26}$ Any antioxidant compounds able to cross the cell membrane could enter the interior of the cells during the incubation period. Following the exposure to products, erythrocytes were washed twice with PBS to remove any compounds that were not absorbed by the cells. Erythrocytes were then loaded with the indicator dye DCF-DA that becomes fluorescent when oxidized, and the peroxyl free radical generator AAPH added to trigger oxidation. Relative fluorescence intensity was measured at $488 \mathrm{~nm}$ using a Tecan Spectrafluor plate reader (Tecan, Männedorf, Switzerland). The baseline was defined by the low fluorescence intensity of the untreated control cells (cells treated with PBS but no test product or AAPH). The positive control was defined by erythrocytes exposed to AAPH alone resulting in maximum oxidative damage. When a reduction of fluorescence intensity was observed in erythrocytes exposed to a test product prior to exposure to AAPH, it was indicative of a test product that contained antioxidants able to penetrate the cells and thus protect them from oxidative damage.

\section{Apoptosis in human primary dermal fibroblasts}

$\mathrm{H}_{2} \mathrm{O}_{2}$ was added to primary dermal fibroblasts to trigger oxidative stress-induced apoptosis, and to assess whether the pretreatment of dermal fibroblasts with test product was able to protect the viability of cells when exposed to oxidative stress. Human dermal fibroblasts were cultured to approximately $80 \%$ confluence. Cells were then exposed to products for 30 minutes, products removed, and cells treated with $1 \mathrm{mM}$ $\mathrm{H}_{2} \mathrm{O}_{2}$ for 1 hour. $\mathrm{H}_{2} \mathrm{O}_{2}$ was removed and the cells trypsinized and stained with CellEvent ${ }^{\mathrm{TM}}$ Caspase-3/7 Green Flow Cytometry Assay kit (Thermo Fisher Scientific) and acquired by flow cytometry using an Attune ${ }^{\circledR}$ acoustic focusing cytometer. Data was analyzed for either the absence (viable cells) or presence (apoptotic cells) of activated Caspase-3/7, indicated by green fluorescence. Testing was performed where each testing condition (negative, positive controls, and each serial dilution of test product) was conducted in duplicate. Negative controls consisted of cells not exposed to test products or 
$\mathrm{H}_{2} \mathrm{O}_{2}$, and positive controls consisted of cells exposed to $\mathrm{H}_{2} \mathrm{O}_{2}$ in the absence of test products.

\section{Intracellular glutathione levels in human primary dermal fibroblasts}

ThiolTracker ${ }^{\mathrm{TM}}$ Violet is a bright and robust intracellular thiol probe for reproducible detection of intracellular levels of reduced glutathione. ${ }^{27}$ Since reduced glutathione represents the majority of intracellular free thiols in the cell, ThiolTracker ${ }^{\mathrm{TM}}$ Violet can be used to estimate the cellular level of reduced glutathione by flow cytometry. In the current study, human dermal fibroblasts were cultured to approximately $80 \%$ confluence, at which time cells were treated with test products for 30 minutes. Test products were removed and oxidative stress conditions induced by $\mathrm{H}_{2} \mathrm{O}_{2}$ treatment ( $1 \mathrm{mM}$ for 1 hour). Pilot work determined that a 1-hour treatment with $\mathrm{H}_{2} \mathrm{O}_{2}$ resulted in a $40 \%-50 \%$ reduction in intracellular reduced glutathione levels. Following treatment with $\mathrm{H}_{2} \mathrm{O}_{2}$, cells were stained with ThiolTracker ${ }^{\mathrm{TM}}$ Violet, detached by trypsinization, and acquired by flow cytometry using an Attune ${ }^{\circledR}$ acoustic focusing cytometer. Data were analyzed for changes in fluorescence intensity, which reflects the reduced glutathione level in the cells. Negative controls consisted of cells not exposed to test products or $\mathrm{H}_{2} \mathrm{O}_{2}$, and positive controls consisted of cells exposed to $\mathrm{H}_{2} \mathrm{O}_{2}$ in the absence of test products.

\section{PMN cell production of reactive oxygen species}

Human PMN cells were used for testing effects of a product on reactive oxygen species (ROS) formation. ${ }^{28}$ Freshly purified human PMN cells were exposed to serial dilutions of the test products. Cells were then washed and loaded with the indicator dye DCF-DA, which turns fluorescent upon exposure to ROS. Formation of ROS was triggered by addition of $\mathrm{H}_{2} \mathrm{O}_{2}$ (2 $\mathrm{mM}$ for 45 minutes). Cells were washed, transferred to cold RPMI-1640 medium, and stored in the dark on ice. Fluorescence intensity was evaluated by flow cytometry using an Attune ${ }^{\circledR}$ acoustic focusing cytometer. The low fluorescence intensity of untreated control cells served as a baseline and PMN cells treated with $\mathrm{H}_{2} \mathrm{O}_{2}$ alone served as a positive control. The testing was performed on PMN cells from three different healthy donors.

\section{Expression of CD69 on leukocyte subsets}

Peripheral whole blood was drawn from three human donors and used to establish cultures where $40 \mu \mathrm{L}$ of blood was combined with $140 \mu \mathrm{L}$ of RPMI-1640 medium containing $1 \times$ penicillin/streptomycin. Serial dilutions of products or lipopolysaccharides $(10 \mathrm{ng} / \mathrm{mL})$ were added to cultures in a volume of $20 \mu \mathrm{L}$ and cultures incubated at $37^{\circ} \mathrm{C}, 5 \% \mathrm{CO}_{2}$ for 24 hours. Each condition was assayed in triplicate. Untreated controls consisted of cells exposed to PBS in the absence of test products. After 24 hours, blood cells were isolated from each culture well and stained for 15 minutes with $10 \mu \mathrm{L}$ of CD69-fluorescein isothiocyanate monoclonal antibody. Cells were then fixed and red blood cells lysed using Cal-Lyse ${ }^{\mathrm{TM}}$ whole blood lysing solution, following manufacturer's instructions. Flow cytometry was performed with an Attune acoustic focusing flow cytometer. Data analysis utilized gating on the forward/side scatter to evaluate CD69 expression on lymphocyte, monocyte/macrophage and PMN cell subsets.

\section{Cytokine profiles from whole blood} cultures and dermal fibroblast cultures

Supernatants were harvested from human whole blood (three donors) and dermal fibroblast 24-hour cultures, and concentrations of 40 cytokines and chemokines were analyzed. IL-1 $\beta$, IL-2, IL-4, IL-6, IL-8 (CXCL8), IL-10, IL-16, interferon $\gamma(\mathrm{IFN}-\gamma)$, tumor necrosis factor $\alpha$ (TNF- $\alpha)$, macrophage migration inhibitory factor (MIF), granulocyte-macrophage colony-stimulating factor (GM-CSF), I-309 (CCL1), eotaxin (CCL11), eotaxin-2 (CCL24), eotaxin-3 (CCL26), macrophage inflammatory protein $1 \alpha$ (MIP-1 $\alpha$ ) (CCL3), MIP-3 $\alpha$ (CCL20), MIP-3ß (CCL19), MCP-1 (CCL2), MCP-2 (CCL8), MCP-3 (CCL7), MCP-4 (CCL13), MIP-5 (CCL15), TARC (CCL17), 6Ckine (CCL21), MDC (CCL22), MPIF-1 (CCL23), TECK (CCL25), CTACK (CCL27), Gro- $\alpha$ (CXCL1), Gro- $\beta$ (CXCL2), ENA-78 (CXCL5), GCP-2 (CXCL6), MIG (CXCL9), IP-10 (CXCL10), I-TAC (CXCL11), SDF-1 $\alpha$ (CXCL12), BCA-1 (CXCL13), SCYB16 (CXCL16), and fractalkine (CX3CL1) were quantified using Bio-Plex protein arrays (Bio-Rad Laboratories Inc) and utilizing $\mathrm{xMAP}^{\circledR}$ technology (Luminex, Austin, TX, USA).

\section{Statistical analysis}

Averages and standard deviations for each data set were calculated using Microsoft Excel. Statistical analysis of in vitro data was performed using the two-tailed, dependent $t$-test. Statistical significance was designated as $P<0.05$, and a high level of significance was designated as $P<0.01$.

\section{Results}

\section{Antioxidant capacity}

The antioxidant capacity of the two $N$. oleander extracts were compared in the Folin-Ciocalteu assay, and ALOE was included as a control. The antioxidant capacity of the NAE- $8^{\circledR}$ extract 
was stronger than the AQ-NOE, and the ALOE only contributed minimally to this effect (Figure 1). The difference in antioxidant capacity between the two extracts was statistically significant across the concentration range of $3-25 \mathrm{~mL} / \mathrm{L}$.

\section{Cellular antioxidant protection}

The relative cellular antioxidant protection was tested in the CAP-e bioassay that uses human erythrocytes as a cellular model for cellular antioxidant uptake and protection from free radical damage. The importance of the erythrocyte model is that this cell type does not produce free radicals as part of intercellular communication or apoptosis. ${ }^{26}$ Therefore, when reduced intracellular oxidative stress is seen in the presence of a test product, the data can be conclusively interpreted, as in the current study: the test product contained antioxidants capable of entering and protecting the cells. Using this model, the NAE- $8^{\circledR}$ provided a significantly better cellular antioxidant protection than the AQ-NOE across a concentration range of $1-33 \mathrm{~mL} / \mathrm{L}$ (Figure 2). The ALOE did not contribute to this effect; in contrast, the ALOE increased the cellular oxidative stress at the highest concentration tested. Therefore, it can be concluded that the antioxidants in NAE- $8^{\circledR}$ capable of entering and protecting cells from oxidative stress were not derived from the ALOE.

\section{Protection of dermal fibroblasts from apoptosis}

Pretreatment of dermal fibroblasts for 30 minutes with serial dilutions of NAE- $8^{\circledR}$ and AQ-NOE extracts protected cells from

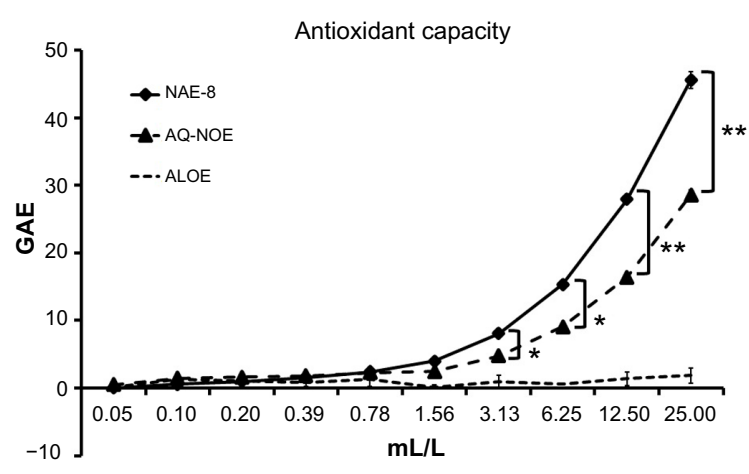

Figure I The concentration-dependent antioxidant capacity for the Aloe vera-based Nerium oleander extract (NAE- $8^{\circledR}$ ) and the aqueous $\mathrm{N}$. oleander extract (AQ-NOE) are shown as gallic acid equivalents (GAE). The very minor antioxidant capacity of Aloe gel alone (ALOE) is shown as a control, since NAE- ${ }^{\circledR}$ is extracted using this gel in the process. The antioxidant capacity of NAE- $8^{\circledR}$ was higher than that of AQ-NOE.

Notes: Levels of significance of data sets when comparing matching concentrations of NAE- $8^{\circledR}$ to the AQ-NOE are indicated by asterisks. Significance $P<0.05$ is indicated by $*$, and a high level of significance $P<0.01$ is indicated by $* *$. Samples were assayed in duplicate. Data are presented as the mean \pm SD.

Abbreviation: SD, standard deviation.

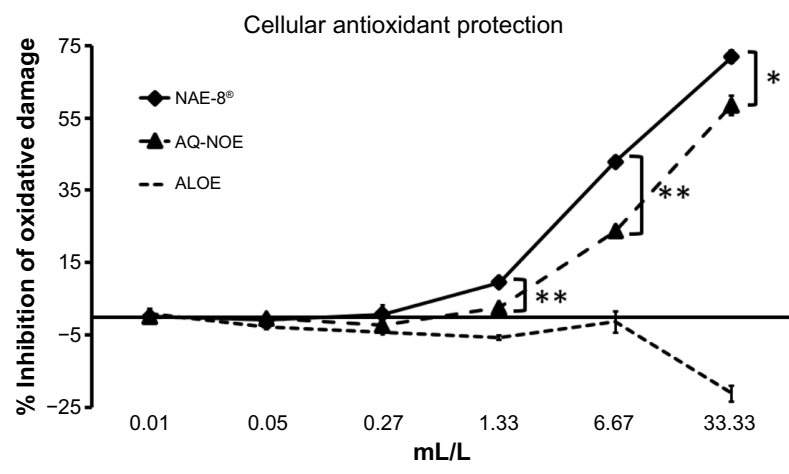

Figure 2 The cellular antioxidant protection provided in the CAP-e assay by the Aloe vera-based Nerium oleander extract $\left(\mathrm{NAE}-8^{\circledR}\right)$ and the aqueous $N$. oleander extract (AQ-NOE) is shown as percent (\%) inhibition of intracellular oxidative damage. The cellular antioxidant protection of Aloe vera gel alone (ALOE) is shown as a control, since NAE- $8^{\circledR}$ is extracted using this material in the process. The antioxidant capacity of NAE- $8^{\circledR}$ was higher than that of AQ-NOE. ALOE did not contribute to this protective effect, demonstrating that the compounds in NAE- $8^{\circledast}$ capable of entering into and protecting cells from oxidative damage were not derived from Aloe.

Notes: Levels of significance of data sets when comparing matching concentrations of the NAE- $8^{\circledR}$ to the AQ-NOE are indicated by asterisks: significance $P<0.05$ is indicated by $*$, and a high level of significance $P<0.0 \mathrm{I}$ is indicated by $* *$. Samples were assayed in duplicate. Data are presented as the mean \pm SD.

Abbreviations: SD, standard deviation; CAP-e, cellular antioxidant protection of erythrocytes.

apoptosis following a 1-hour exposure to $\mathrm{H}_{2} \mathrm{O}_{2}$ (Figure 3). The three highest concentrations of NAE- $8^{\circledR}$ and AQ-NOE resulted in $35 \%-55 \%$ higher viability than dermal fibroblasts that were not pretreated with products prior to exposure to $\mathrm{H}_{2} \mathrm{O}_{2}$.

\section{Protection of intracellular glutathione stores}

Pretreatment of dermal fibroblasts for 30 minutes with serial dilutions of NAE- $8^{\circledR}$ and AQ-NOE extracts protected cells

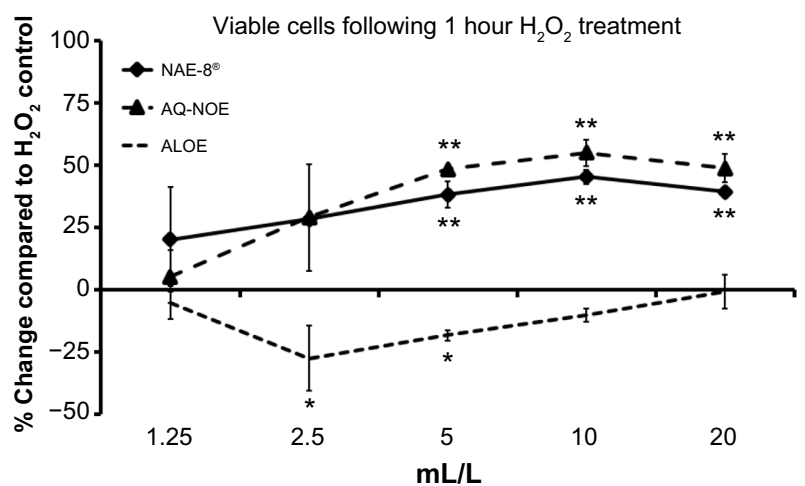

Figure 3 The viability of dermal fibroblasts treated with $\mathrm{H}_{2} \mathrm{O}_{2}$ for I hour either alone or following a 30-minute incubation with test products. Results are represented as the \% change compared to the $\mathrm{H}_{2} \mathrm{O}_{2}$ treated control. The three highest concentrations of both the aqueous Nerium oleander extract (AQ-NOE) and the Aloe vera-based N. oleander extract $\left(\mathrm{NAE}-\mathrm{8}^{\circledR}\right)$ resulted in a $35 \%-55 \%$ protection from apoptosis. Conversely, pretreatment with serial dilutions of ALOE (aloe gel alone) did not lead to protection. Notes: Significance $P<0.05$ is indicated by ${ }^{*}$, and a high level of significance $P<0.01$ is indicated by $* *$. Samples were assayed in duplicate. The data are representative of two different experiments with similar results. Data are presented as the mean \pm SD. Abbreviation: SD, standard deviation. 
from oxidation of intracellular glutathione following a 1-hour exposure to $\mathrm{H}_{2} \mathrm{O}_{2}$ (Figure 4). Pretreatment of cells with the two highest concentrations of NAE- $8^{\circledR}$ and the highest concentration of AQ-NOE resulted in a reduction in oxidation of intracellular glutathione following $\mathrm{H}_{2} \mathrm{O}_{2}$ treatment.

\section{Inhibition of ROS production}

An inflammatory response is typically associated with free radical formation via several different pathways, including the formation of ROS by inflammatory cells such as PMN cells. ${ }^{29}$ In the present study, when ROS formation was induced by an inflammatory insult in PMN cells previously treated with the test products, a significant reduction in ROS formation was observed when compared to the level of ROS induction in untreated cells (Figure 5). In parallel, when PMN cells were exposed to test products in the absence of an inflammatory insult, both NAE- $8^{\circledR}$ - and AQ-NOE-treated PMN cells showed a significant reduction of baseline ROS levels (Figure 6). The ALOE did not contribute to the antiinflammatory effects seen for similar concentration ranges of the NAE- $8^{\circledR}$ extract.

\section{Activation of leukocyte subsets}

Treatment of whole blood cultures with lipopolysaccharide or the $0.2 \mathrm{~mL} / \mathrm{L}$ dilution of AQ-NOE resulted in an increase in CD69 expression on lymphocytes, monocytes, and PMN cells from all three donors (Figure 7). The highest concentration of NAE- $8^{\circledR}(0.2 \mathrm{~mL} / \mathrm{L})$ showed a slight increase in CD69

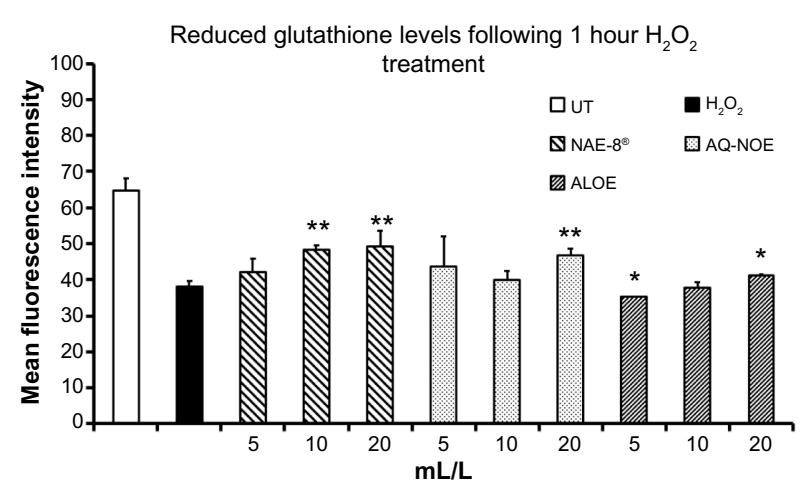

Figure 4 Intracellular reduced glutathione levels in dermal fibroblasts treated with $\mathrm{H}_{2} \mathrm{O}_{2}$ for I hour either alone or following a 30-minute incubation with test products. Results are shown as the mean fluorescence intensity of the ThiolTracker ${ }^{\text {TM }}$ Violet indicator dye divided by a factor of 1,000 . The two highest concentrations of the Aloe vera-based Nerium oleander extract $\left(\mathrm{NAE}-8^{\circledR}\right)$ and the highest concentration of the ALOE (Aloe gel alone) and aqueous $N$. oleander extract (AQ-NOE) protected intracellular reduced glutathione levels in dermal fibroblasts exposed to oxidative stress.

Notes: Statistical significance was calculated by comparing to cells treated with $\mathrm{H}_{2} \mathrm{O}_{2}$ in the absence of test products, and is indicated by $* P<0.05$, and $* * P<0.01$. Untreated (UT) cell cultures are shown as a control. Samples were assayed in duplicate. The data are representative of three different experiments. Data are presented as the mean $\pm S D$.

Abbreviation: SD, standard deviation.

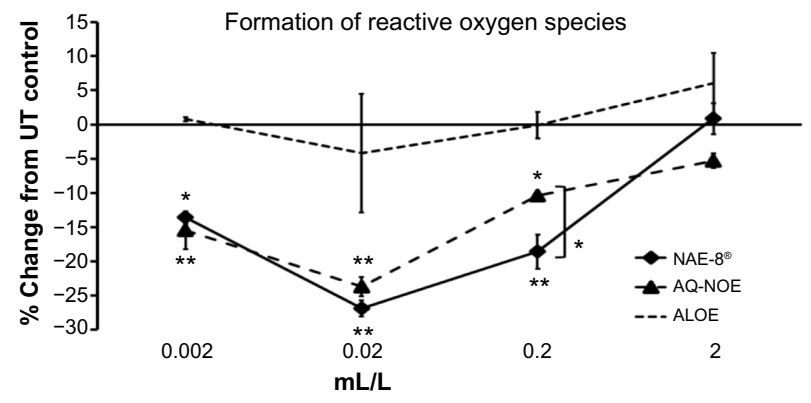

Figure 5 The inflammation-induced intracellular formation of reactive oxygen species (ROS) in polymorphonuclear (PMN) cells is shown as the percent (\%) change relative to untreated PMN cells. Samples were assayed in triplicate and the data shown are representative of three separate experiments using PMN cells from three different healthy adult donors. Both the Aloe vera-based Nerium oleander extract $\left(\mathrm{NAE}-\mathrm{8}^{\circledR}\right.$ ) and the aqueous $\mathrm{N}$. Oleander extract (AQ-NOE) inhibited ROS formation across a similar concentration range, and the inhibition at concentrations between $0.002-0.2 \mathrm{~mL} / \mathrm{L}$ was statistically significant when compared to PMN cells not exposed to test product $(* P<0.05, * * P<0.01)$. At the concentration of 0.2 $\mathrm{mL} / \mathrm{L}$, the NAE-8 ${ }^{\circledR}$ performed significantly better than the AQ-NOE $(* P<0.05)$. In comparison, Aloe gel alone (ALOE) did not contribute to this anti-inflammatory effect, suggesting that the compounds in NAE- $8^{\circledR}$ responsible for the reduced ROS production were not derived from the $A$. vera used during extraction.

Note: Data are presented as the mean \pm SD.

Abbreviations: SD, standard deviation; UT, untreated.

expression on monocytes, but this was significant for only one of the three donors.

\section{Production of cytokines and chemokines in human whole blood cultures}

Results of Luminex testing of 40 cytokines and chemokines on human whole blood cultures exposed to the $0.2 \mathrm{~mL} / \mathrm{L}$

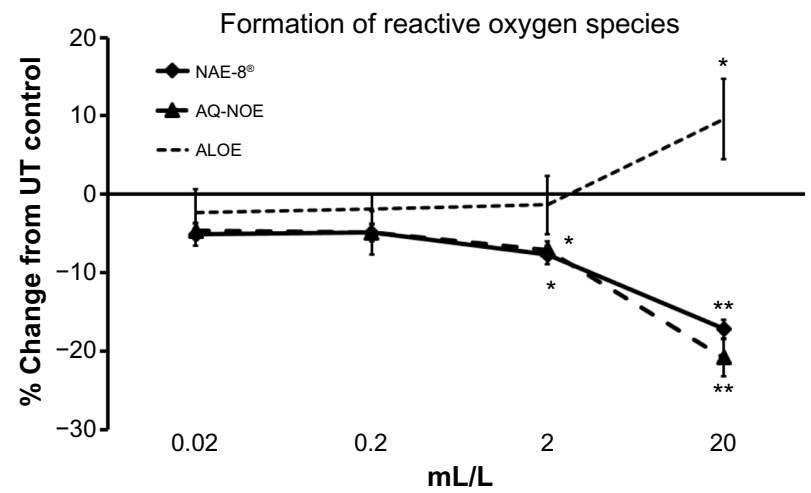

Figure 6 The levels of intracellular formation of reactive oxygen species (ROS) in non-inflamed polymorphonuclear (PMN) cells (in the absence of induced oxidative stress) is shown as the percent (\%) change, relative to untreated PMN cells. Samples were assayed in triplicate, and the data shown are representative of three similar experiments using PMN cells from three different healthy adult donors. Both the Aloe vera-based Nerium oleander extract (NAE-8 ${ }^{\circledR}$ ) and the aqueous N. Oleander extract (AQNOE) inhibited ROS formation across a similar concentration range, and the inhibition at concentrations between $2-20 \mathrm{~mL} / \mathrm{L}$ was statistically significant when compared to PMN cells not exposed to test product $(* P<0.05$, $* * P<0.01)$. In comparison, Aloe gel alone (ALOE) did not contribute to this anti-inflammatory effect, suggesting that the compounds in $\mathrm{NAE}-8^{\circledR}$ responsible for the reduced ROS production were not derived from the ALOE used during extraction, but were derived from $N$. oleander.

Note: Data are presented as the mean \pm SD.

Abbreviations: SD, standard deviation; UT, untreated. 

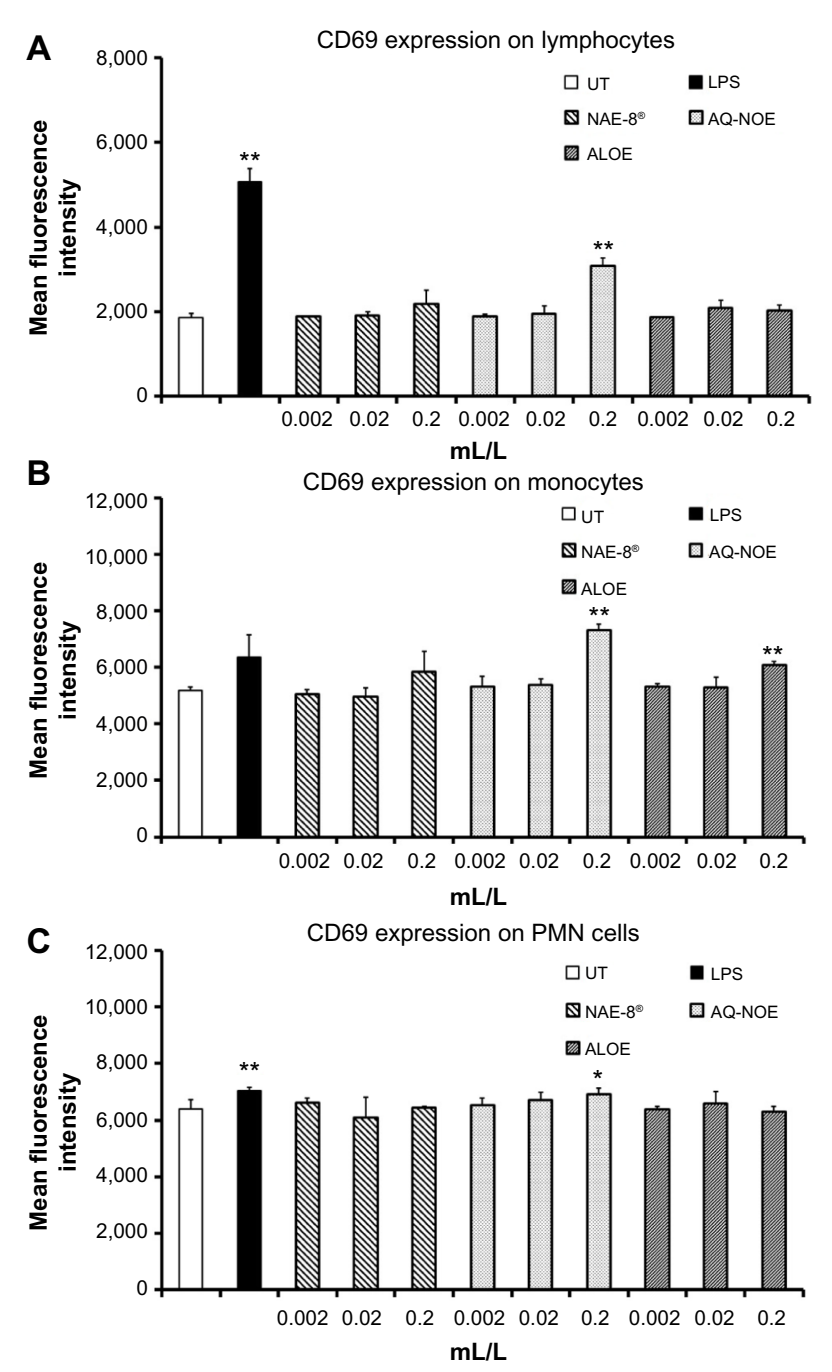

Figure 7 CD69 expression on lymphocyte (A), monocyte (B), and polymorphonuclear (PMN) cell (C) populations in 24-hour whole blood cultures. Samples were assayed in triplicate, and mean fluorescence intensity data are shown and are representative of three separate experiments using whole blood from three different healthy human donors. In all three cell types, exposure to the highest dose of the aqueous Nerium oleander extract (AQ-NOE) resulted in an increase in CD69 expression. Lipopolysaccharide (LPS) was used as a positive control $(10 \mathrm{ng} / \mathrm{mL})$ and resulted in an increase in CD69 expression on all three cell types. In the case of monocytes, the $0.2 \mathrm{~mL} / \mathrm{L}$ concentration of AQ-NOE activated cells better than LPS. Monocytes were also activated by the $0.2 \mathrm{~mL} / \mathrm{L}$ concentration of Aloe vera gel alone (ALOE).

Notes: Statistical significance is indicated by asterisks with * indicating $P<0.05$ and

** indicating $P<0.01$. Data are presented as the mean \pm SD.

Abbreviations: SD, standard deviation; UT, untreated; NAE- $8^{\circledR}$, Aloe vera-based Nerium oleander extract.

dilution of products for 24 hours are shown in Table 1. Each value represents an average of the concentration $(\mathrm{pg} / \mathrm{mL})$ from the three donors. Treatment with AQ-NOE resulted in an increase in cytokine/chemokine concentrations in cultures. Treatment with ALOE resulted in mostly no change or decreases in cytokine/chemokine concentrations in cultures. Treatment with NAE- $8^{\circledR}$ resulted in responses in cytokine/chemokine concentrations in cultures that were in between the responses seen with ALOE or AQ-NOE extract treatment alone.

\section{Production of cytokines and chemokines in human dermal fibroblast cultures}

Results of Luminex testing of seven cytokines and chemokines on human dermal fibroblast cultures are shown in Figure 8. Of the 40 cytokines and chemokines tested, only seven were above detectable levels. Treatment with ALOE resulted in increases in cytokine/chemokine concentrations in dermal fibroblast cultures only. Treatment with AQ-NOE resulted in both increases and decreases in cytokine/chemokine concentrations in dermal fibroblast cultures. In some cases (IL-8, MCP-1, and CXCL11) treatment with NAE-8 ${ }^{\circledR}$ resulted in changes in cytokine/chemokine concentrations in dermal fibroblast cultures that were unique to NAE- $8^{\circledR}$, and could not be accounted for by a simple averaging of the responses seen with ALOE or AQ-NOE treatments alone.

\section{Discussion}

The data presented in the current study is, to the best of our knowledge, the first research to establish the unique bioactivities of a novel extract of $N$. oleander, using ALOE instead of an aqueous-based extraction of bioactive compounds for topical use. The goal of this work was to examine cellular antioxidant protection by several parallel assays, as well as a more in-depth examination of cellular communication compounds (cytokines) between dermal fibroblasts and circulating leukocytes, the latter representing cells present in the microcirculation of the skin, as well as in the skin tissue.

The testing of anti-oxidant capacity in the Folin-Ciocalteu antioxidant capacity assay showed superior antioxidant capacity of NAE- $8^{\circledR}$ compared to AQ-NOE or ALOE. Furthermore, testing of cellular antioxidant protection using the CAP-e assay showed that NAE- $8^{\circledR}$ contains more antioxidants that are bioavailable at the cellular level, compared to AQ-NOE. Interestingly, ALOE did not contribute to the cellular antioxidant protection by NAE- ${ }^{\circledR}$, suggesting that the Aloe-based extraction used for producing NAE- $8^{\circledR}$ allows increased extraction of biologically relevant compounds. This erythrocyte model is crucial for the interpretation of cellular antioxidant uptake, since the erythrocyte does not contain mitochondria, therefore allowing a reduction of intracellular oxidative damage to be conclusively linked to cellular antioxidant uptake.

Further testing of cellular antioxidant protection involved bioassays using human primary dermal fibroblasts, and showed comparable protection by NAE- $8^{\circledR}$ and AQ-NOE from loss of viability and protection of intracellular reduced glutathione stores when cells were placed under oxidative stress. Glutathione is an important cellular antioxidant and 
Table I Levels $(\mathrm{pg} / \mathrm{mL})$ of 40 cytokines/chemokines in WB culture supernatants

\begin{tabular}{|c|c|c|c|c|c|}
\hline Cytokine & UT & LPS & NAE-8 ${ }^{\circledR}$ & AQ-NOE & ALOE \\
\hline IL-I $\beta$ & $2.1 \pm 1.67$ & $974.61 \pm 612.47^{*}$ & $5.08 \pm 3.98 @$ & $207.25 \pm \mid 60.61 *$ & $2.64 \pm 1.87$ \\
\hline IL-2 & $1.87 \pm 0.25$ & $13.23 \pm 0.86 * *$ & $1.91 \pm 0.4 @$ & $5.95 \pm 3.17^{*}$ & $\mathrm{I} .8 \mathrm{I} \pm 0.63$ \\
\hline IL-4 & $3.6 \mathrm{I} \pm 1.22$ & $\mid 6.34 \pm I^{* *}$ & $3.76 \pm 1.12^{@}$ & $8.2 \pm 4.24^{*}$ & $3.18 \pm 1.45$ \\
\hline IL-6 & $10.98 \pm 3.15$ & $|0| 3 \mid, .85 \pm 1,748.65 *$ & $25 \pm 8.76$ *\# & $930.17 \pm 989.68$ & $10.95 \pm 5.57$ \\
\hline IL-8 & || $7.7 \mid \pm 93.88$ & $3,526.66 \pm 1,167.96 * *$ & 233.48土156.3@ & $2,4 \mid 9.47 \pm 2,019.21 *$ & $94.15 \pm 65.16$ \\
\hline IL-10 & $5.13 \pm 1.19$ & $124.05 \pm 43.87 * *$ & 6.06I.71@ & $22.17 \pm 13.74 *$ & $5.06 \pm 0.6 \mathrm{I}$ \\
\hline IL-16 & $201.28 \pm 43.07$ & $285.48 \pm 19.75^{* *}$ & $159.2 \pm 12.14 @, * *$ & $208.08 \pm 30.91$ & $160.29 \pm 15.66$ \\
\hline IFN- $\gamma$ & $2.89 \pm 1.44$ & $219.28 \pm 219.44$ & $3.42 \pm 1.23^{@}$ & $20.75 \pm 15.86 *$ & $2.48 \pm 0.6 \mathrm{I}$ \\
\hline TNF- $\alpha$ & $9.07 \pm 0.93$ & I,330.88₫564.73** & $9.92 \pm 0.52 *, \#, @$ & $47.45 \pm 34.29 *$ & $8.31 \pm 0.5^{*}$ \\
\hline MIF & $4,9 \mid 4.98 \pm 2,540.82$ & $5,520.86 \pm 2,233.47$ & $3,690.04 \pm 1,737.98$ & $3,626.85 \pm 816.77$ & $5,280.78 \pm 2,844.22$ \\
\hline GM-CSF & $1 \mid 4.9 \pm 12.52$ & $205.45 \pm 13.16^{* *}$ & $125.47 \pm 8.33$ & $138.88 \pm \mid 2.99 * *$ & $|26.04 \pm| 4.77$ \\
\hline 1-309 & $16.93 \pm 3.28$ & $80.12 \pm 3.06 * *$ & 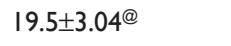 & $44.82 \pm 22.77^{*}$ & $16.49 \pm 2.57$ \\
\hline MCP-I & $784.74 \pm 763.22$ & $3,644.24 \pm 768.84 * *$ & $922.15 \pm 596.99 @$ & 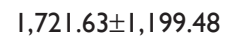 & $433.19 \pm 264.21$ \\
\hline MIP-Ia & $7 \pm 4.97$ & $19,073.2 \pm 2 \mid, 547.95$ & 14.23土13.26@ & $340.15 \pm 259.38 *$ & $6.28 \pm 4.85$ \\
\hline MCP-3 & $15.49 \pm 7.24$ & $|33.1| \pm 2 \mid .54 * *$ & I8.73 $\pm 3.24^{\#, @ ~}$ & $47.73 \pm 32.76$ & $12.39 \pm 2.62$ \\
\hline MCP-2 & $6.01 \pm 0.65$ & $609.69 \pm 309.68 * *$ & $6.77 \pm 1.06^{@}$ & $12.68 \pm 5.72 *$ & $5.94 \pm 1.18$ \\
\hline Eotaxin & || $.87 \pm 0.9 \mid$ & $43.8 \pm 1.44 * *$ & 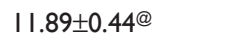 & $23.3 \pm 9.26^{*}$ & $11.98 \pm 0.73$ \\
\hline MCP-4 & $9.19 \pm 3.28$ & $30.35 \pm 8.3 * *$ & $10.08 \pm 3.57 @$ & $18.72 \pm 6.27 *$ & $9.03 \pm 4.13$ \\
\hline MIP-5 & $931.94 \pm 140.76$ & $1,055.89 \pm 196.52$ & $926.38 \pm 158.77$ & $971.19 \pm 172.27$ & $964.8 \pm 188.65$ \\
\hline TARC & $|3.4| \pm 4.73$ & $38.31 \pm 6.4^{* *}$ & $|6.01 \pm 4.7|$ & $25.72 \pm 12.4$ & $13.48 \pm 3.85$ \\
\hline MIP-3 $\beta$ & $12.7 \pm 4.96$ & $58.19 \pm|4.4| * *$ & 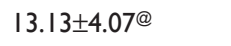 & $24.66 \pm 9.76 *$ & $11.99 \pm 5.23$ \\
\hline MIP-3 $\alpha$ & $10.85 \pm 11.37$ & $214.22 \pm 74.74 * *$ & $12.63 \pm 10.27$ & $172.5 \pm 196.42$ & $5.3 \pm 5.19$ \\
\hline 6Ckine & $1,253.13 \pm 112.12$ & $\mathrm{I}, 466.5 \mathrm{I} \pm \mathrm{I} 67.08 *$ & $1,224.85 \pm 161.62$ & $1,298 \pm 116.82$ & $1,241.16 \pm 34.96$ \\
\hline MDC & $67.06 \pm 18.36$ & $198.96 \pm 66.25 * *$ & $67.39 \pm 17.19$ & II $3.42 \pm 64.02$ & $64.61 \pm 12.67$ \\
\hline MPIF-I & $31.93 \pm 16.37$ & $191.38 \pm 86.93 * *$ & $30.84 \pm 17.54$ & $40.31 \pm 10.92$ & $31.48 \pm 19.65$ \\
\hline Eotaxin-2 & $59.8 \pm 10.91$ & $56.33 \pm 1.94$ & $80.02 \pm 11.93 * *, \# @$ & $\mid 40.93 \pm 52.86 *$ & $57.93 \pm 5.38$ \\
\hline TECK & $22.09 \pm 7.03$ & $285.05 \pm 18.76$ ** & $21.04 \pm 4.34^{@}$ & || $8.2 \mid \pm 83.23 *$ & $30.62 \pm 22.41$ \\
\hline Eotaxin-3 & $8.72 \pm|.5|$ & $31.85 \pm 2.15^{* *}$ & $8.76 \pm 1.08$ & $18.34 \pm 7.46^{*}$ & $10.4 \pm 5.86$ \\
\hline CTACK & $25.17 \pm 22.06$ & $31.4 \pm 25.13$ & $21.15 \pm 18.66$ & $25.67 \pm 25.25$ & $26.57 \pm 25.16$ \\
\hline Gro- $\alpha$ & $76.83 \pm 7.19$ & $377.08 \pm 66.19^{* *}$ & $87.36 \pm 11.88^{\#}$ & $313.25 \pm 248.13$ & $73.63 \pm 3.64$ \\
\hline Gro- $\beta$ & $17.32 \pm 4.12$ & $67.08 \pm 8.26 * *$ & $19.24 \pm 2.67$ & $65.77 \pm 53.85$ & $17.62 \pm 2.5$ \\
\hline ENA-78 & $|56| \pm 28$. & $782.11 \pm \mid 28.28^{* *}$ & I76.58土42.66@ & $477.5 \pm 295.39 *$ & $\mid 44.26 \pm 32.48$ \\
\hline GCP-2 & $1.59 \pm 1.26$ & $|2.38 \pm 3.9| * *$ & $0.79 \pm 0.02$ & $5.39 \pm 6.33$ & $0.84 \pm 0.17$ \\
\hline MIG & $16.82 \pm 1.92$ & $47.45 \pm 2.27^{* *}$ & 15.8土2.89@ & $25.08 \pm 6.32 *$ & $16.23 \pm 1.21$ \\
\hline IP-10 & $10.77 \pm 0.75$ & $|48.75 \pm 49.8| * *$ & 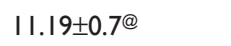 & $|7.68 \pm 6.1|^{*}$ & $10.35 \pm 1.07$ \\
\hline I-TAC & $6.39 \pm 2.64$ & $12.22 \pm 3.63^{* *}$ & $6.52 \pm 2.77$ & $8.23 \pm 3.83$ & $6.74 \pm 2.24$ \\
\hline SDF-I $\alpha$ & $46.23 \pm 4.74$ & II $5.96 \pm 8.29 * *$ & $48.5 \pm 8.15$ & $69.49 \pm 30.6$ & $43.58 \pm 3.21$ \\
\hline BCA-I & $0.4 I \pm 0$ & $4.11 \pm 3.29 *$ & $0.4 I \pm 0$ & $0.41 \pm 0$ & $0.72 \pm 0.46$ \\
\hline SCYBI6 & $177.99 \pm 46.39$ & $\mid 84.73 \pm 34.34$ & $183.7 \pm 54.26$ & $186.17 \pm 50.5$ & $181.98 \pm 50.43$ \\
\hline Fractalkine & $28.06 \pm 14.04$ & $230.69 \pm 56.84^{* *}$ & $32.76 \pm|3.5|$ & $170.14 \pm 159.57$ & $20.37 \pm 5.15$ \\
\hline
\end{tabular}

Notes: $* * * *$ Statistical significance $\left(P<0.05, P<0.0\right.$ I, respectively) when comparing treatments to untreated controls (UT); ${ }^{*}$ statistical significance $(P<0.01$, with the exception of Gro- $\alpha$ where $P<0.05)$ when comparing NAE- $8^{\circledR}$ to ALOE; ${ }^{\circledR}$ statistical significance $(P<0.0 \mathrm{I})$ when comparing NAE- $8^{\circledR}$ to AQ-NOE.

Abbreviations: UT, untreated; LPS, lipopolysaccharide; NAE- $8^{\circledR}$, Aloe vera-based Nerium oleander extract; AQ-NOE, aqueous extract of N. oleander; ALOE, A. vera alone.

functions as a cofactor for several cellular detoxification enzymes. Its role in the mitochondria includes protecting cells from the damaging effects of excessive ROS, leading to the triggering of apoptosis. ${ }^{30}$

The effects of each extract on immune cells was tested in whole blood cultures to allow optimal cross-talk between different cell types present in the microcirculation in skin tissue, as well as cytokine production in dermal fibroblast cultures and what this could mean in the skin. The presence of various immune regulatory cells in the skin, and the programming of these cells toward pro- versus anti-inflammatory activity, has a profound effect on skin health. ${ }^{31}$ Furthermore, the cross-talk between immune cells and skin cells is important in up- or down-regulating inflammatory conditions in the skin, as well as the initiation of repair mechanisms..$^{32,33}$

The treatment of whole blood cultures with AQNOE led to an overall induction of multiple cytokines/ chemokines, while ALOE treatment led to the production 


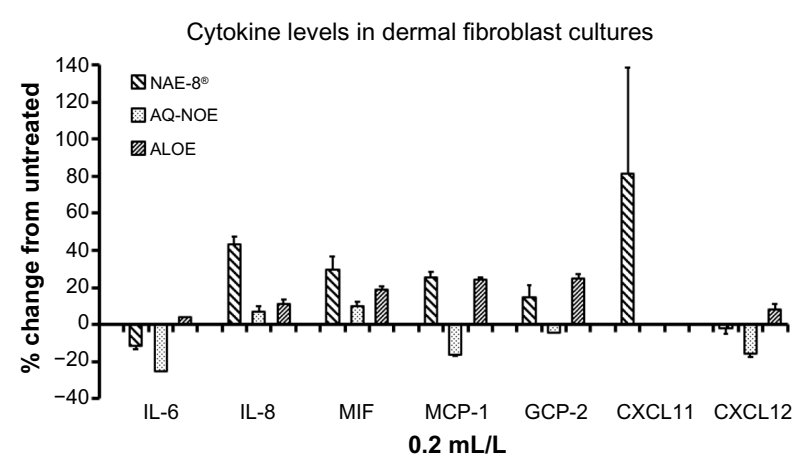

Figure 8 Changes in cytokine levels in cultures of dermal fibroblasts exposed to either Aloe vera gel alone (ALOE), $A$. vera-based Nerium oleander extract (NAE-8 ${ }^{\circledR}$ ), or aqueous $N$. oleander extract (AQ-NOE). Results are shown as percent (\%) change from untreated control cultures. Of the 40 cytokines and chemokines tested, only seven reached detectable levels in the culture supernatants. The strong induction of $\mathrm{CXCLII}$ by the NAE-8 ${ }^{\circledR}$ extract was not seen for either ALOE or AQ-NOE. Samples were assayed in duplicate.

Note: Data are presented as the mean $\pm S D$

Abbreviation: SD, standard deviation.

of cytokine/chemokine levels similar to that of untreated cultures. The array included pro- and anti-inflammatory chemokines, of which a large number involve monocytespecific, skin-specific, and inflammation-resolving factors, which have been shown to be secreted by dermal fibroblasts after treatment with burn wound exudates. ${ }^{34}$ The array also includes factors associated with the chemokine profile seen in skin blisters during the resolution of an inflammatory response. ${ }^{35}$ Interestingly, in our current study, NAE- $8^{\mathbb{R}}$ had selective effects on cytokine production in the whole blood cultures that were more moderate than those elicited by AQ-NOE.

The treatment of dermal fibroblasts with NAE- $8^{\circledR}$ resulted in a robust induction of CXCL11 in dermal fibroblasts. A role has recently been shown for CXCL11 in re-epithelialization during wound healing. ${ }^{36}$ The effects on cytokine/chemokine production, unique to NAE- $8^{\circledR}$, included increases in production of IL-8, MIF, MCP-1, and GCP-2, cytokines involved in the recruitment/chemotaxis of monocytes and granulocytes. This is interesting in light of evidence that fibroblasts maintain neutrophil viability both in culture and in the tissue microenvironment, suggesting that the production of these cytokines by dermal fibroblasts in response to NAE- $8^{\circledR}$ points to effects relevant to interactions between dermal fibroblasts and immune cells in the skin. ${ }^{37,38}$ Furthermore, IL-8 and MCP-1 have been shown to play a role in altering collagen I and hyaluronan production when added to human dermal fibroblast cultures. ${ }^{39}$

The data presented here also provide a basis to argue that the topical treatment of skin with the NAE- $8^{\circledR}$ extract is safe, both for dermal cells and for immune cells present in the skin and in the microvasculature. The treatment of cells did not compromise cellular viability, nor did it induce cellular oxidative stress; on the contrary, there was a significant reduction in cellular oxidative stress in cells treated with the NAE- $8^{\circledR}$ extract, both in the absence and in the presence of an inflammatory insult. The method of inducing oxidative stress in this study aimed at mimicking the oxidative stress after ultraviolet radiation, so the reduced cellular oxidative stress after NAE- $8^{\circledR}$ treatment may suggest a role for NAE- $8^{\circledR}$ in skin care associated with reduction of injury, as well as potential repair of sun damage.

\section{Conclusion}

The overall conclusion from the results presented here is that the NAE- $8^{\circledR}$ extract has multiple beneficial effects to a cellular antioxidant protection system, and reduces cellular free radical production, both in the absence and in the presence of an inflammatory insult. Future work should include examination of the unique chemical profile associated with Aloe-based extraction of $N$. oleander leaves, when compared to a hot water extract, especially in the light of the improved safety and efficacy profile at the cellular level. The efficacy of skin treatment with NAE- $8^{\circledR}$ before as well as after UV exposure is also in need of further ongoing clinical evaluation.

\section{Acknowledgments}

The study was conducted at NIS Labs, an independent contract research laboratory specializing in natural products research. The study was sponsored by Nerium Biotechnology, Inc.

\section{Disclosure}

KFB and GSJ are employed by NIS Labs, an independent contract research laboratory specializing in natural products research. RAN serves as Chief Science Officer for Nerium Biotechnology, the sponsor of the study. The authors report no other conflicts of interest in this work.

\section{References}

1. Hamman JH. Composition and applications of Aloe vera leaf gel. Molecules. 2008;13(8):1599-1616.

2. Fowler JF Jr, Woolery-Lloyd H, Waldorf H, Saini R. Innovations in natural ingredients and their use in skin care. J Drugs Dermatol. 2010;9(Suppl 6): S72-S81.

3. Fox LT, du Plessis J, Gerber M, van Zyl S, Boneschans B, Hamman JH. In vivo skin hydration and anti-erythema effects of Aloe vera, Aloe ferox and Aloe marlothii gel materials after single and multiple applications. Pharmacogn Mag. 2014;10 (Suppl 2):S392-S403.

4. Moniruzzaman M, Roykeya B, Ahmed S, Bhowmik A, Khalil MI, Gan SH. In vitro antioxidant effects of Aloe barbadensis Miller extracts and the potential role of these extracts as antidiabetic and antilipidemic agents on streptozotocin-induced type 2 diabetic model rats. Molecules 2012;17(11):12851-12867. 
5. Hossain MS, Mamun-Or-Rashid ANM, Tofique NM, Sen MK. A review on ethnopharmacological potential of Aloe vera L. J Intercult Ethnopharmacol. 2013;2(2):113-120.

6. Dey P, Chaudhuri TK. Pharmacological aspects of Nerium indicum Mill: a comprehensive review. Pharmacogn Rev. 2014;8(16):156-162.

7. Duke JA. Handbook of Medicinal Herbs. Boca Raton, FL: CRC Press; 1985.

8. Tantiado RG. Survey on ethnopharmacology of medicinal plants in Iloilo, Philippines. Int J Biosci Biotechnol. 2012;4:11-26.

9. Bhuvaneshwari L, Arthy E, Anitha C, Dhanabalan K, Meena M. Phytochemical analysis and antibacterial activity of Nerium oleander. Anc Sci Life. 2007;26(4):24-28.

10. Singh S, Shenoy S, Nehete PN, et al. Nerium oleander derived cardiac glycoside oleandrin is a novel inhibitor of HIV infectivity. Fitoterapia. 2013;84:32-39.

11. Fu L, Zhang S, Li N, et al. Three new triterpenes from Nerium oleander and biological activity of the isolated compounds. J Nat Prod. 2005;68(2):198-206.

12. Wójciak-Kosior M, Paduch R, Matysik-Woźniak A, Niedziela P, Donica $\mathrm{H}$. The effect of ursolic acid and oleanolic acids on human skin fibroblast cells. Folia Histochem Cytobiol. 2011;49(4): 664-669.

13. Lin Y, Dubinsky WP, Ho DH, Felix E, Newman RA. Determinants of human and mouse melanoma cell sensitivities to oleandrin. $J$ Exp Ther Oncol. 2008;7(3):195-205.

14. Rajapakse S. Management of yellow oleander poisoning. Clin Toxicol (Phila). 2009;47(3):206-212.

15. Eddleston M. Applied clinical pharmacology and public health in rural Asia- preventing deaths from organophosphorus pesticide and yellow oleander poisoning. Br J Clin Pharmacol. 2013;75(5): $1175-1178$

16. Newman RA, Yanp P, Hittleman WN, et al. Oleandrin-mediated oxidative stress in human melanoma cells. J Exp Ther Oncol. 2006;5(3): $167-181$.

17. Lim SW, Hong SP, Jeong SW, et al. Simultaneous effect of ursolic and oleanolic acid on epidermal permeability barrier function and epidermal keratinocyte differentiation via peroxisome proliferator-activated receptor-alpha. J Dermatol. 2007;34(9):625-634.

18. Rong ZT, Gong XJ, Sun HB, Li YM, Ji H. Protective effects of oleanolic acid on cerebral ischemic damage in vivo and $\mathrm{H}_{2} \mathrm{O}_{2}$-induced injury in vitro. Pharm Biol. 2011;49(1):78-85.

19. Liu J, Wu Q, Lu YF, Pi J. New insights into generalized hepatoprotective effects of oleanolic acid: key roles of metallothionein and Nrf2 induction. Biochem Pharmacol. 2008;76(7):922-928.

20. Galgon T, Wohlrab W, Dräger B. Betulinic acid induces apoptosis in skin cancer cells and differentiation in normal human keratinocytes. Exp Dermatol. 2005;14(10):736-743.

21. Liu J. Pharmacology of oleanolic acid and ursolic acid. JEthnopharmacol. 1995;49(2):57-68.

22. Amaro-Ortiz A, Yan B, D; Orazio JA. Ultraviolet radiation, aging and the skin: prevention of damage by topical cAMP manipulation. Molecules. 2014;19(5):6202-6219.

23. Bill H McAnalley, inventor; Carrington Laboratories, Inc., assignee. Process for Preparation of Aloe Products. US patent 4,957,907. September 18, 1990.
24. Donald L Smothers, inventor; Nerium Biotechnology, Inc., assignee. Plant Extraction Method and Compositions. US Patent No 8,524,286. September 3, 2013.

25. Singleton VL, Orthofer R, Lamuela-Raventos RM. Analysis of total phenols and other oxidation substrates and antioxidants by means of folin-ciocalteu reagent. Methods Enzymol. 1999;299C:152-178.

26. Honzel D, Carter SG, Redman KA, Schauss AG, Endres JR, Jensen GS. Comparison of chemical and cell-based antioxidant methods for evaluation of foods and natural products: generating multifaceted data by parallel testing using erythrocytes and polymorphonuclear cells. JAgric Food Chem. 2008;56(18):8319-8325.

27. Mandavilli BS, Janes MS. Detection of intracellular glutathione using ThiolTracker violet stain and fluorescence microscopy. Curr Protoc Cytom. 2010;9(9):35.

28. Benson KF, Beaman JL, Ou B, Okubena A, Okubena O, Jensen GS. West African Sorghum bicolor leaf sheaths have anti-inflammatory and immune-modulating properties in vitro. J Med Food. 2013;16(3): 230-238.

29. Mittal M, Siddiqui MR, Tran K, Reddy SP, Malik AB. Reactive oxygen species in inflammation and tissue injury. Antioxid Recos Signal. 2014;20(7):1126-1167.

30. Ribas V, García-Ruiz C, Fermández-Checa JC. Glutathione and mitochondria. Front Pharmacol. 2014;5:151.

31. Ploeger DT, Hosper NA, Schipper M, Koerts JA, de Rond S, Bank RA. Cell plasticity in wound healing: paracrine factors of M1/M2 polarized macrophages influence the phenotypical state of dermal fibroblasts. Cell Commun Signal. 2013;11(1):11-29.

32. Almine JF, Wise SG, Hiob M, et al. Elastin sequences trigger transient proinflammatory responses by human dermal fibroblasts. FASEB $J$. 2013;27(9):3455-3465.

33. Gaspar K, Kukova G, Bunemann E, et al. The chemokine receptor CCR3 participates in tissue remodeling during atopic skin inflammation. $J$ Dermatol Sci. 2013;71(1):12-21.

34. van den Broek LJ, Kroeze KL, Waaijman T, et al. Differential response of human adipose tissue-derived mesenchymal stem cells, dermal fibroblasts, and keratinocytes to burn wound exudates: potential role of skin-specific chemokine CCL27. Tissue Eng Part A. 2014;20(1-2): 197-209.

35. Evans BJ, Haskard DO, Sempowksi G, Landis RC. Evolution of the macrophage CD163 phenotype and cytokine profiles in a human model of resolving inflammation. Int J Inflam. 2013;2013:780502.

36. Tortelli F, Pisano M, Briquez PS, Martino MM, Hubbell JA. Fibronectin binding modulates CXCL11 activity and facilitates wound healing. PLoS One. 2013;8(10):e79610.

37. Ling CJ, Owen WF Jr, Austen KF. Human fibroblasts maintain the viability and augment the functional response of human neutrophils in culture. J Clin Invest. 1990;85(2):601-604.

38. Filer A, Parsonage G, Smith E, et al. Differential survival of leukocyte subsets mediated by synovial, bone marrow, and skin fibroblasts: sitespecific versus activation-dependent survival of T cells and neutrophils. Arthritis Rheum. 2006;54(7):2096-2108.

39. Kim MS, Song HJ, Lee SH, Lee CK. Comparative study of various growth factors and cytokines on type I collagen and hyaluronan production in human dermal fibroblasts. J Cosmet Dermatol. 2014;13(1): $44-51$.
Clinical, Cosmetic and Investigational Dermatology

\section{Publish your work in this journal}

Clinical, Cosmetic and Investigational Dermatology is an international, peer-reviewed, open access, online journal that focuses on the latest clinical and experimental research in all aspects of skin disease and cosmetic interventions. All areas of dermatology will be covered; contributions will be welcomed from all clinicians and

\section{Dovepress}

basic science researchers globally. This journal is indexed on CAS The manuscript management system is completely online and includes a very quick and fair peer-review system, which is all easy to use. Visit http://www.dovepress.com/testimonials.php to read real quotes from published authors 